\title{
Presepsin: Sepsis Tespiti İçin Umut Verici Yeni Bir Biyobelirteç
}

\section{Presepsin: A Promising Novel Biomarker for the Detection of Sepsis}

\author{
${\text { Meltem Malkoç }{ }^{1 *}, \text { Birgül Vanizor Kural }}^{2}$ \\ ${ }^{1}$ Karadeniz Teknik Üniversitesi, Sağlık Hizmetleri Meslek Yüksek Okulu, Trabzon,Türkiye \\ ${ }^{2}$ Karadeniz Teknik Üniversitesi Tıp Fakültesi, Tıbbi Biyokimya, Trabzon, Türkiye \\ e-mail: meltemmalkoc69@gmail.com, bvanizorkural@ktu.edu.tr \\ ORCID: 0000-0002-8652-941X \\ ORCID: 0000-0003-0730-9660 \\ *Sorumlu yazar/ Corresponding Author: Meltem Malkoç \\ Gönderim Tarihi / Received: 27.02.2021 \\ Kabul Tarihi / Accepted: 01.06.2021 \\ DOI: $10.34087 /$ cbusbed.887818
}

\begin{abstract}
$\ddot{O} z$
Sistemik inflamatuar yanıt sendromu (SIYS) olarak da tanımlanan sepsis, hayatı tehdit eder boyutta seyreden çoklu organ fonksiyon bozukluğu olarak tanımlanmaktadır. Sepsis gibi ciddi bakteriyel enfeksiyonlarda erken teşhis, bulaşıcı hastalıkların tedavisi ve kontrolü için oldukça önem arz etmektedir. Ancak, bakteriyel enfeksiyonların tanınmasındaki ana problem, belirti ve semptomların klinik görünümünün sıklıkla diğer enflamatuvar bozukluklarla örtüşmesidir. Enfeksiyonların teşhisinde mikrobiyolojik, biyokimyasal ve moleküler yöntemler yaygın kullanılmasına rağmen, duyarlılık ve özgüllük açısından bazı sınırlamaları mevcuttur. Bu nedenle henüz altın standart bir belirteç ortaya konulamamıştır. Önerilen biyobelirteçlerin, uygun maliyetli, hızlı, basit, güvenilir, spesifik ve hassas yöntemlerle belirlenebilmesi gerekmektedir.

Presepsin, çözünür farklılaşma kümesi 14 (SCD14-ST) alt tipi olarak da bilinen bir proteindir. T ve B hücreleri ile direkt etkileşime girerek hücresel ve humoral bağışıklık sistemini düzenler. Bakteriyel enfeksiyonlara yanıt olarak artmakta ve antibiyotik tedavisinden sonra azalmaktadır. Bu nedenle de, istilacı bir patojene karşı immün hücre yanıtının aktivasyonunun bir göstergesi olarak düşünülmektedir. Ayrıca sepsis için erken bir biyobelirteç olabileceği ileri sürülmektedir.

Presepsin, genel dolaşımda kararlı olması ve sistemik enfeksiyonun ilk aşamasının aday bir biyobelirteç olması nedeniyle son yıllardaki çalışmalarda önemli yer edinmiştir. Literatürde presepsin hakkında araştırma makalesi ve derleme sayısı her geçen gün artmaktadır. Bu derlemenin amacı, klinisyenlere rehber olması açısından büyük yararlar sağlayacak presepsin ölçümünün sepsisdeki yeri ve önemi diğer sepsis biyobelirteçleri göz önüne alınarak değerlendirmektir.
\end{abstract}

Anahtar Kelimeler: Biyobelirteç, sCD14-ST, Enfeksiyon, Presepsin, Sepsis.

\footnotetext{
Abstract

Sepsis, also defined as systemic inflammatory response syndrome, is defined as life-threatening multi-organ dysfunction. Early diagnosis in severe bacterial infections such as sepsis, is very important for the treatment and control of infectious diseases. However, the basic problem in recognizing bacterial infections is that the signs and symptoms often overlap with the clinical symptom of other inflammatory disorders. Although microbiological, biochemical and molecular methods have been widely used in the diagnosis of infections, they have some limitations in terms of sensitivity and specificity. Therefore, a gold standard indicator has not been revealed yet. The proposed biomarkers should be determined by cost-effective, fast, simple, reliable, specific and sensitive methods.

Presepsin is a new protein also known as soluble cluster of differentiation 14 (sCD14-ST) subtype. It regulates the cellular and humoral immune system by directly interacting with $\mathrm{T}$ and $\mathrm{B}$ cells. It increases in response to bacterial infections and decreases after antibiotic therapy. Therefore, it is considered as an indicator of activation of the immune cell response against an invading pathogen. It is also suggested that it may be an early biomarker for sepsis.
} 
Presepsin has gained an important place in recent studies due to its stability in the general circulation and being a candidate biomarker of the first stage of systemic infection. The number of research articles and reviews about presepsin is increasing day by day in the literature. The purpose of this review is to evaluate the place and importance of presepsin measurement in sepsis, considering other sepsis biomarkers, which will provide great benefits to clinicians.

Keywords : Sepsis, presepsin, sCD14-ST, biyomarker, infection

\section{Giriş}

Sepsis, patolojik enfeksiyona karşı gelişen, organizmanın düzensiz inflamatuvar durum ile etkisi artan ve çoklu organ yetmezliği ile sonuçlanan sistemik inflamatuvar yanıt sendromudur (SİYS). İlerleyen süreçte, şiddetli sepsis, septik şok ve çoklu organ fonksiyon kayb1 gelişebilir [1]. Her yıl dünya çapında milyonlarca kişinin ölümüne neden olan yüksek morbidite ve mortalite ile önemli bir sağlık sorunları arasında yer almaktadır. Hastanede yatanların \%1-2'sinde ve yoğun bakım ünitesi (YBÜ) hastalarının \% 25'inin sepsis gelişebilmektedir [2]. Uygun olmayan antimikrobiyal tedavi ile tanı ve tedavinin geciktirilmesi, sepsis ile ilişkili yüksek morbidite ve mortalitenin ana nedenidir. $\mathrm{Bu}$ nedenle sepsis teşhisi ve prognozu için uygun maliyetli, hızlı, basit, güvenilir, spesifik ve hassas biyobelirteç ortaya koymak önemlidir [3].

Biyobelirteçler kanda, diğer vücut sıvilarında ve dokularda inflamatuvar durumları ayırt etmeye yardımcı olan, tanı ve tedaviye yanıtta yararlanılan moleküllerdir. Genel olarak, enfeksiyonların tespiti için mikrobiyolojik kültür yöntemleri, biyokimyasal, immünolojik ve moleküler yöntemler kullanılmaktadır. Bu yöntemlerin analiz maliyeti yüksek olup, ekipman ve yetkin eleman gerektirmektedir [4]. Kan kültürleri, sepsis teşhisi için altın standarttır. Büyük avantajları olmasına rağmen, kan kültürlerinin bazı sınırlamaları vardır, özellikle daha önce antibiyotiklerle tedavi edilen hastalarda sonuçlar genellikle negatiftir. Ayrıca uzun süren kültür sonuçlarını beklerken, kritik septik hastaların tedavisi gecikebilir ve bu da kötü sonuç olasılığını artırabilir [5].

Sepsis teşhisi için yaklaşı 258 biyobelirteç belirlenmiştir [6]. İdeal olan biyobelirteç, yüksek hassasiyet ve özgüllüğü korumalı, uygun maliyetli ve hemen ulaşılabilir olmalıdır. Ancak klinik görünümünün sıklıkla diğer inflamatuvar bozukluklarla uyuşması nedeniyle sepsis ve infeksiyöz olmayan SIYS durumlarını ayırt edebilmede mevcut biyobelirteçler yeterince spesifik değildir [2,7].

Sepsiste birçok biyobelirteç kullanılabilir, ancak hiçbirinin klinik uygulamada rutin olarak kullanılması için yeterli özgüllüğü veya duyarlılığı yoktur. Sepsis biyobelirteçlerinin çoğu inflamatuvar sürecin ara ürünleri ve proinflamatuvar sitokinlerdir. Sepsis değerlendirmesinde ve hasta takibinde en yaygın olarak kullanilan prokalsitonin (PCT) ve C-reaktif protein (CRP) biyobelirteçleri bile sepsisi diğer enflamatuar durumlardan ayırt etme veya sonucu tahmin etme yetenekleri sınırlıdır [8].Bir akut faz reaktantı olan CRP herhangi bir enfeksiyon ve travma sonrası arttığı için bakteriyel enfeksiyonlar için sınırlı özgüllüğe sahiptir. Bir pro hormon olan PCT ise hastalığın prognozu ile ilişkili olarak CRP'ye göre daha belirleyici olduğu kanıtlanmıştır. PCT takibi ile tedavinin antibiyotik kullanımını azalttığı gösterilmiştir. Ancak bu biyobelirtecinde hala bazı önemli sınırlamaları vardır. Septik olmayan koşullarda örneğin invazif travma, cerrahi, sıcak çarpması ve fiziksel egzersizde geçici olarak yükselme eğilimindedir. Presepsin, ise sepsis için yüksek duyarlılığa ve iyi özgüllüğe sahip yeni bir biyobelirteçtir. Acil serviste kolayca uygulanabilir ve ciddi sepsis ve septik şoklu hastaların hastane içi mortalitesi ile önemli ölçüde ilişkilidir [9,10].

Farklı tanısal ve prognostik değere sahip akut enfeksiyonlar için test edilen ümit verici yeni biyobelirteçler ise miyeloid hücreler-1 (sTREM-1), proadrenomedullin (pro-ADM), çözünür ürokinaz tipi plazminojen reseptörü (suPAR) ve presepsindir [11]. Ayrıca son yıllardaki araştırmalar, mikroRNA'ların, uzun kodlamayan RNA'ların ve insan mikrobiyomunun sepsiste biyobelirteç olabileceklerini göstermiştir [12].

$\mathrm{Bu}$ derlemenin amac1, klinisyenlere rehber olması açısından büyük yararlar sağlayacak presepsin ölçümünün genel dolaşımda kararlı olması ve sistemik enfeksiyonun ilk aşamasında belirlenebilmesi nedeniyle sepsisteki yeri ve önemi diğer sepsis biyobelirteçleri göz önüne alınarak değerlendirmektir.

\section{Presepsinin Yapısı ve Oluşumu}

CD14, makrofaj, nötrofil gibi miyeloid kökenli hücrelerde bulunan çözünür farklılaşma kümesi olarak isimlendirilen ve özellikle bakteriyal enfeksiyonlarda rolü olan doğal immün sistemin bir bileşenidir. CD14, hem Gram pozitif hem de Gram negatif patojenlerin çeşitli ligand gruplarını, (lipidler, peptidoglikan ve diğer yüzey bileşenlerini) ve hasarla ilişkili moleküler kalıpların (PAMP) tanınmasında anahtar bir role sahip olan çok işlevli bir glikoproteindir [13]. Presepsin, CD14'ün $13 \mathrm{kDa}$ N-terminal kesik fragmanıdır. Genellikle, doğuştan gelen bağışıklık hücrelerinin yüzeyinde, özellikle monositler ve makrofajlar tarafından eksprese edilir ve lipopolisakkarite (LPS) yüksek affiniteye sahiptir [14]. CD14'ün iki biçimi vardır: membrana bağlı CD14 (mCD14) ve çözünür CD14 (sCD14). Membran bağl1 CD14, toll benzeri reseptörlerin (TLR'ler) bir koreseptörü olarak işlev görür. Enfeksiyöz ajanların veya enfeksiyöz olmayan uyaranların varlığında CD14, TLR-4'ü aktive eder. Bu da proinflamatuar hücre içi sinyal iletim kaskadı ve nükleer faktörü kappa B (NF-kB)'nin aktivasyonu ile sonuçlanır. Sonuçta tümör nekroz faktör alfa (TNF- $\alpha$ ), interferon-gama (IFN- $\gamma$ ), interlökin-1 $\beta$ (IL-1 $\beta$ ), IL-6 ve IL-8 gibi proinflamatuar sitokinlerin ekspresyonuna yol açar [15]. İnflamatuar kaskadın aktivasyonu yoğun ve aşırı sistemik inflamatuar yanıtı 
tetikleyebilir ve pıhtılaşmayı ve fibrinolitik sistemleri aktive ederek SİYS, sepsis şoku, yaygın intravasküler pıhtılaşma ve çoklu organ disfonksiyon sendromuna neden olabilir. $\mathrm{Bu}$ sürece, zara bağlı ve hücrelerden fagosite edilen CD14'ün dolaşıma atılması eşlik eder. Çözünür CD14 (sCD14) daha sonra plazma proteazları tarafından işlenir ve bu da presepsin olarak da adlandırılan çözünür CD14 alt tipinin (sCD14-ST) üretilmesine neden olur [16] (Şekil 1).

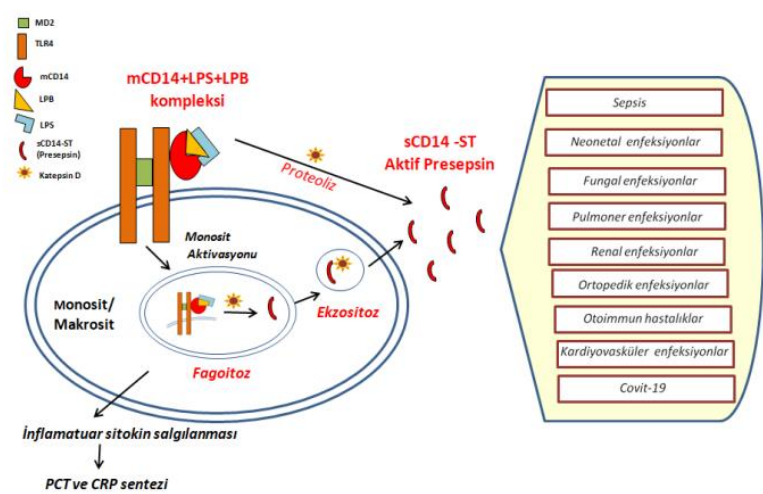

Şekil 1. Presepsin oluşum mekanizması ve hastalıklarla ilişkisi [12-15, 28,29]. Çözünür CD14 alt tipi (sCD14ST) veya presepsin, sCD14 üzerinden plazma proteazlarının etkisi ile üretilir. Moleküler kompleks mCD14-LPS-LBP, fagozitozla hücre içine alınır. Katepsin D etkisi ile proteolik olarak presepsin oluşur ve bu da dolaşıma ekzoitoz ile salınır. CD14: membran CD14 (mCD14), MD2: moleküler dinamik-2; LBP: Lipoprotein Bağlayıcı Protein, LPS: lipopolisakkarit, TLR4: Toll benzeri reseptör.

\section{Presepsinin Biyolojik Önemi}

Presepsin son zamanlarda sepsiste prognostik bir biyobelirteç olarak çeşitli klinik araştırma gruplarının dikkatini çekmiştir. Presepsinin biyolojik aktivitesi ayrıntılı olarak açıklanamamıştır. Ancak, bir düzenleyici faktör olarak tanımlanmıştır. Plazma presepsin seviyeleri, invazif patojenlere yanıt olarak aktive edilmiş doğal immün efektör hücrelerin bir göstergesi olarak kabul edilebilir [14]. Doğrudan T ve B hücreleri ile etkileşime girerek hücresel ve humoral bağışıklık sistemini düzenler. Ayrıca endotoksin şokunun neden olduğu ölüm oranını ve enfeksiyonların şiddetini azaltabilir. Dolaşımdaki presepsin seviyeleri, patojenlere yanıt olarak aktive edilmiş monosit-makrofajın bir göstergesi olarak algılanabilir [17].

Dahada önemlisi sCD14 reseptörleri, serbest ligand için membrana bağlı formlarla rekabet edebilir, böylece sitokin salınımını önleyebilir ve lipoproteinlere, lipopolisakkarit transferini kolaylaştırabilir. $\mathrm{Bu}$ nedenle sCD14, kısmen B hücreleri tarafından immünoglobulin üretimini ve bağ 1 șiklık sisteminini artırarak antiinflamatuvar bir rol oynayabilir. CD14 ayrıca kritik hastalıklarda TLR4'ten bağımsız bir şekilde metabolik düzenleyici olarak rol oynayabilir [18]. Plazma presepsin seviyeleri bakteriyel enfeksiyon yanıt olarak yükselmekte ve antibiyotik tedavisinden sonra azalmaktadır. $\mathrm{Bu}$ nedenle, istilacı bir patojene karşı immün hücre yanıtının bir göstergesi olarak düşünülmektedir [10]. Presepsin sekresyonunun monosit fagositozuyla ilişkili olduğu da gösterilmiştir bu nedenle, enfekte olmayan sağlıklı deneklerde de ölçülebilir. CD14 dolaşımdaki monosit zarında bulunduğundan, lökosit sayısının presepsin düzeylerini etkileyebileceği öne sürülmesine rağmen presepsin düzeylerinin lökosit sayımı ile ilişkisi tespit edilememiştir. $\mathrm{Bu}$ nedenle, presepsinin sağlıklı, enfekte olmayan, bireylerde bile ölçülebilir olması, bakteriyel enfeksiyonların erken aşamasında artması ve doğuştan gelen immün sistemin yoğunluğuna bağlı olması gerektiğini önermektedir [15].

\section{Sepsisde Presepsinin Rolï}

Sepsis için spesifik bir biyobelirteç yoktur. Enfeksiyon ayırımında bir standart olmadığı için sepsisi, özellikle bulaşıcı olmayan SIYYS'dan ayırmak zordur [14]. Son zamanlarda yapılan araştırmalar presepsin düzeylerindeki değişikliğin, şiddetli sepsis veya septik şok vakalarında prognozu iyileştiren ve hayatta kalma oranını artıran antibiyotik tedavisinin izlenmesi için uygun bir gösterge olduğunu göstermiştir [15]. Zhao ve ark, sepsisle ilişkili akut respiratuar distres sendromunun (ARDS) erken dönemde belirlenmesinde yüksek plazma presepsin seviyelerinin, ARDS'de artmış mortalite ile ilişkili olduğunu bildirdiler [19]. Presepsinin yoğun bakım hastalarında yüksek duyarlılık ve özgüllük değeri ile çok güçlü bir mortalite ön belirteci olduğu gösterildi [20]. Akut abdominal rahatsızlıkları olan hastalarda sepsis oluşumunu tahmin etmek için presepsin plazma düzeylerinin duyarlılığı ve özgüllüğü belirlendiği bir başka çalışmada presepsin değerleri sağlıklı, SiYS ve sepsis grubu için sirasiyla $258.7 \pm 92.53 \mathrm{ng} / \mathrm{L}$, $30.0 \pm 141.33 \mathrm{ng} / \mathrm{L}, 1508.3 \pm 866.6 \mathrm{ng} / \mathrm{L}$ olarak bildirildi [21]. 191 hasta ile yapılan gözlemsel bir başka çalışmada presepsin, tek başına, PCT'e kıyasla SIYYS'yi sepsiden ayırt etmede daha yüksek tanısal doğruluğa sahip olduğu raporlanmıştır [22]

Ancak sepsiste presepsinin etkinliği ile ilgili literatürde tartışmalı sonuçlarda mevcuttur. Presepsin, sepsis tanısı için etkili bir yardımcı biyobelirteçtir, ancak tek başına kullanıldığında sepsisi saptamak veya dışlamak için yetersiz olabilmektedir [23]. Presepsin biyolojisinin mekanik açıdan sağlam yönlerinin klinik olarak tam olarak nasıl kullanılabileceğini belirlemek gerekmeklidir [24]. Endo ve ark. sinırlı enfeksiyonu olan hastalarda sepsisli hastalara göre, anlamlı derecede yüksek presepsin seviyeleri bulamamışlardır [25]. Presepsin hakkında çok önemli bir bilgide, presepsin küçük bir protein olduğundan $(13 \mathrm{kDa})$ ve böbrekler tarafından filtrelendiğinden, seviyesi büyük ölçüde böbrek fonksiyonuna bağlıdır. Azalan glomerüler filtrasyon, dolaşımda yüksek presepsin seviyelerine neden olur ve bu nedenle böbrek yetmezliği olan hastalarda cut-off değerinin üzerindeki presepsin seviyeleri dikkatle yorumlanmalıdır [23]. Presepsin konsantrasyonu yaş (yeni doğanlar ve yaşlı bireyler), böbrek fonksiyon bozukluğu, bakteriyemi ve hemofagositik sendrom (HPS) gibi bazı patofizyolojik koşullar etkileyebilir [11]. Ayrıca presepsin değerleri dahil edilen çalışmalarda oluşturulan grupların heterojenitesinden, çalışma 
stratejisinden, klinik ortam (acil servis, YBÜ), hasta tip (yetişkinler veya yeni doğan), sepsis için kriterler ve hatta kullanılan örnek türü (plazma, serum veya tam kan) gibi farklılıklardan kaynaklanabilir [11,26].

Presepsin, hızlı farmakokinetiğe sahip bir moleküldür. Genel olarak presepsin seviyesi enfeksiyonda 2 saat sonra yükselir; 3 saat sonra zirveye ulaşır ve 7 . günde azalmaya başlar. Presepsinin bu spesifik özelliği, onu bakteriyel veya fungal enfeksiyonlarda önemli ölçüde daha uzun kinetiğe sahip olan prokalsitonin veya CReaktif proteine göre üstün bir biyobelirteç haline getirir. Presepsinin plazma yarılanma ömrü 4-5 saat, prokalsitonin ise 20-24 saat, CRP ise 18-19 saattir. Bu bulgu, presepsinin bakterilere karşı konakçı tepkisinin yararlı bir belirteci olabileceğini ve hem enfeksiyonun spesifik bir belirteci hem de mevcut belirteçlere kıyasla erken bir gösterge olabileceğini doğrulayabilir [22,23]. Yenidoğan sepsisi, özellikle erken doğmus bebeklerde çoklu organ işlev bozukluğunda hızla ilerleyebildiğinden, erken teşhis sağ kalımı iyileştirmek için kritik öneme sahiptir. Yenidoğan sepsisin saptanmasında daha duyarlı olması nedeniyle presepsinin PCT ve CRP'den daha yüksek bir tanısal doğruluğa sahip olduğu belirlenmiş ve bu nedenle neonatal sepsisin saptanmasında iyi bir biyobelirteç olabileceği ileri sürülmüştür [27].

Presepsin ölçümü, sadece sepsiste değil son zamanlarda, pulmoner, kardiyovasküler, renal, ortopetik, otoimmun ve koronavirüs-19 (covid-19) gibi yoğun bakımdan mantar enfeksiyonuna kadar değișen farklı klinik uygulama alanları ilgili literatürde çalışmalar mevcuttur (Şekil 1) [28, 29].

\section{Presepsin ölçümü}

Sepsisde klinik tablo kötüleşmeden önce erken teşhis özellikle spesifik tedavi şansını arttırır ve hayatta kalmak için temel belirleyici faktörü temsil etmektedir. Sepsis hastalarının teşhis ve takibinde hız önemli olduğu için presepsin düzeylerinin de belirlenmesi için hasta başında, tam otomatize kısa sürede yüksek duyarlılıkta ve hassasiyette sonuç veren yöntemlere ihtiyaç vardır [30]. Presepsin, genellikle immünassay yöntemlerle belirlenmektedir. Ancak antikor ve özel bir sandviç tekniği kullanılan uygun duyarlılık ve özgüllükle tayin kitleri yaygın kullanılmaktadır. İlk olarak, 4 saat içinde standart olarak rekombinant CD14 (S286C) ile presepsinin saptanması için iki aşamalı geleneksel sandviç enzim bağlantılı immünosorbent deneyi (ELISA) kullanıldı. Ancak bu yöntem YBÜ ve rutin presepsin değerlendirmeleri için hız ve doğruluktan yoksundu. Birkaç yıl sonra, tek aşamalı 1,5 saatte tayin imkanı sağlayan ELISA testi geliştirildi ve rekombinant presepsin ve iki yeni antipresepsin antikoru kullanılarak değerlendirildi. Sonuç olarak, tek adımlı ELİSA testi ile toplam analiz süresi 4 saatten 1.5 saate düşürüldü [31].

Son olarak, tüm kan numunelerini analiz etmek için kemilüminesan enzim immunoassay (CLEIA) prensibine dayalı, oldukça hassas, tam otomatik 17 dakika içinde sonuç veren nispeten basit ve yüksek duyarlılıkta ve özgüllükte bir yöntem geliştirilmiştir [32]. Presepsin seviye belirlenmesi için tam kan da kullanılabilmetedir. $\mathrm{Bu}$ da acil serviste, YBÜ'de ve cerrahi işlem gerektire durumlarda hız bakımından avantaj sağlayabilmektedir.

\section{Sonuç}

Presepsin, sistemik bakteriyel enfeksiyonun tanısal bir belirteci olarak kullanılabilir ve sepsisin ciddiyetini ve sonucunu tahmin etmek de klinisyenlere rehber olma açısından büyük yararlar sağlayabilir. Presepsinin hızlı analiz ve yüksek prognostik değeri nedeniyle, laboratuvarlarda, acil ve yoğun bakım ünitelerinde ve yenidoğan bölümlerinde kullanışı uygundur. Sonuç olarak mükemmel bir prognostik performans ve çeşitli klinik koşullara hızlı yanıt verme yeteneği ile presepsini sepsisde tedaviyi izlemek, erken tanı, doğru antibiyotik dozunu seçmek veya etkisiz ise değiştirmek için ideal bir araç haline getirir. Ancak sepsis yanıtının karmaşıklığından dolayı, klinik uygulamada tek bir biyobelirtecin yeterli olması olası değildir. Diğer sepsis biyobelirteçleri ile birlikte değerlendirilmesi uygun görülebilir.

\section{Referanslar}

1. Dkhil, M.A, Al-Quraishy, S, Moneim, A.E.A, Ziziphus spina-christi leaf extract pretreatment inhibits liver and spleen injury in a mouse model of sepsis via anti-oxidant and anti-inflammatory effects, Inflammopharmacology, 2018, 26 (3), 779-791.

2.Wu, J, Hu, L, Zhang, G, Wu, F, He, T, Accuracy of presepsin in sepsis diagnosis: a systematic review and meta-analysis, PLoS One, 2015, 10 (7), e0133057.

3.Kibe, S, Adams, K, Barlow, G, Diagnostic and prognostic biomarkers of sepsis in critical care, Journal of antimicrobial chemotherapy 2011, 66 (suppl_2), ii33-ii40.

4.Sönmezer, M.Ç, Tülek, N, Bakteriyel Infeksiyonlarda ve Sepsiste iyobelirteçler/Biomarkers in Bacterial Infections and Sepsis, Klimik Dergisi, 2015, 28 (3), 96.

5.Aliu-Bejta, A, Atelj, A, Kurshumliu, M, Dreshaj, S, Baršić B, Presepsin values as markers of severity of sepsis, International Journal of Infectious Diseases, 2020, 95, 1-7.

6. Pierrakos, C, Velissaris, D, Bisdorff, M, Marshall, J.C, Vincent, J.L, Biomarkers of sepsis: time for a reappraisal,Critical Care ,2020, 24, $1-15$.

7. Grondman, I, Pirvu, A, Riza, A, Ioana, M, Netea, M.G, Biomarkers of inflammation and the etiology of sepsis, Biochemical Society Transactions, 2020, 48 (1), 1-14.

8. Henriquez-Camacho, C, Losa, J, Biomarkers for sepsis, BioMed research international, 2014,2014.

9. Özdemir, A.A, Diagnostıc Reliabiiity Of Crp And Procalcitonin in Early-Onset Neonatal Sepsis And The impact Of Fetal Distress (Running T itle: The reliability of CRP and procalcitonin), Int J Basic Clin Med, 2016, 4(3), 118-25.

10.Wu CC, Lan HM, Han ST, Chaou CH, Yeh CF, Liu SH, Chen KF. Comparison of diagnostic accuracy in sepsis between presepsin, procalcitonin, and C-reactive protein: a systematic review and metaanalysis, Annals of intensive care, 2017, 7 (1), 1-16.

11. Marshall, J.C, Reinhart, K, Biomarkers of sepsis, Critical care medicine, 2009, 37 (7), 2290-2298.

12. Szilágyi, B, Fejes, Z, Pócsi, M, Kappelmayer, J, Nagy, Jr B, Role of sepsis modulated circulating microRNAs, Ejifcc, 2019, 30 (2), 128.

13. Kundakci, A, Pirat, A, Toll Benzeri Reseptörler/Toll-Like Receptors, Türk Yogun Bakim Dergisi, 2012, 10(2), 63.

14. Memar, M.Y, Baghi, H.B, Presepsin: a promising biomarker for the detection of bacterial infections, Biomedicine \& Pharmacotherapy, 2019,111, 649-656.

15. Chenevier-Gobeaux, C, Borderie, D, Weiss, N, Mallet-Coste, T, Claessens, Y.E, Presepsin (sCD14-ST), an innate immune response marker in sepsis, Clinica chimica acta 2015,450, 97-103.

16. Zou, Q, Wen, W, Zhang, X.C, Presepsin as a novel sepsis biomarker, World journal of emergency medicine, 2014, 5 (1), 16. 
17. Nores, J.E.R, Bensussan, A, Vita, N, Stelter, F, Arias, M.A, Jones, M, Labéta, M.O, Soluble CD14 acts as a negative regulator of human T cell activation and function, European journal of immunology, 1999, 29 (1), 265-276.

18. Ackland, G.L, Prowle, J.R, Presepsin: solving a soluble (CD14) problem in sepsis? Intensive Care Medicine, 2015, 41, 351-353.

19. Zhao, J, Tan, Y, Wang, L, Shi, Y, Discriminatory ability and prognostic evaluation of presepsin for sepsis-related acute respiratory distress syndrome, Scientific Reports, 2020, 10(1), 1-10.

20. Drăgoescu, A.N, Pădureanu, V, Stănculescu, A.D, Chiuțu, L.C, Florescu, D.N, Gheonea, I.A, Drăgoescu, O.P, Presepsin as a Potential Prognostic Marker for Sepsis According to Actual Practice Guidelines, Journal of Personalized Medicine, 2021,11(1), 2.

21. Vodnik, T, Kaljevic, G, Tadic, T, Majkic-Singh, N, Presepsin (sCD14-ST) in preoperative diagnosis of abdominal sepsis, Clin. Clinical chemistry and Laboratory Medicine, 2013, 51 (10) 2053 2062.

22. Zhang, J, Hu, Z.D, Song, J, Shao, J, Diagnostic value of presepsin for sepsis: A systematic review and meta-analysis, Medicine, 2015, 94 e2158.

23. Rogić, D, Juroš, G. F, Petrik, J, Vrančić, A. L, Advances and pitfalls in using laboratory biomarkers for the diagnosis and management of sepsis, Journal of the International Federation of Clinical Chemistry and Laboratory Medicine, 2017, 28(2), 114.

24.Ackland, Gareth L, John, R, Prowle. Presepsin: solving a soluble (CD14) problem in sepsis? Intensive Care Med, 2015, 41, 351-353.

25. Endo, S, Suzuki, Y, Takahashi, G, Shozushima, T, Ishikura, H, Murai, A, Okamura, Y, Usefulness of presepsin in the diagnosis of sepsis in a multicenter prospective study, Journal of Iinfection and Chemotherapy, 2012,18 (6), 891-897.

26. Godnic, M, Stubjar, D, Skvarc, M, Jukic, T,Diagnostic and prognostic value of sCD14-ST-presepsin for patients admitted to hospita intensive care unit (ICU), Wiener klinische Wochenschrift, 2015, 127 (13), 521-527.

27. Bellos, I, Fitrou, G, Pergialiotis, V, Thomakos, N, Perrea, D.N Daskalakis, G, The diagnostic accuracy of presepsin in neonatal sepsis: a meta-analysis, European journal of pediatrics, 2018, 177 (5), 625-632.

28. Galliera, E, Massaccesi, L, De, Vecchi, E, Banfi, G, Romanelli, M.M.C, Clinical application of presepsin as diagnostic biomarker of infection: overview and updates, Clinical Chemistry and Laboratory Medicine (CCLM), 2019, 58 (1), 11-17.

29. Ali, F.T, Ali, M.A, Elnakeeb, M.M, Bendary, H.N, Presepsin is an early monitoring biomarker for predicting clinical outcome in patients with sepsis, Clinica Chimica Acta, 2016, 460, 93-101.

30. Fukada, A, Kitagawa, Y, Matsuoka, M, Sakai, J, Imai, K, Tarumoto, N, Maeda, T, Presepsin as a predictive biomarker of severity in Covid-19: a case series, Journal of Medical Virology, 2020, 93 (1) 99-101.

31. Shirakawa, K, Naitou, K, Hirose, J, Takahashi, T, Furusako, S, Presepsin (sCD14-ST): development and evaluation of one-step ELISA with a new standard that is similar to the form of presepsin in septic patients, Clinical Chemistry and Laboratory Medicine (CCLM), 2011,49 (5), 937-939.

32. Okamura, Y, Yokoi, H, Development of a point-of-care assay system for measurement of presepsin (sCD14-ST), Clinica Chimica Acta, 2011, 412 (23-24), 2157-2161.

http://edergi.cbu.edu.tr/ojs/index.php/cbusbed isimli yazarın CBU-SBED başlıklı eseri bu Creative Commons Alıntı-Gayriticari4.0 Uluslararası Lisansı ile lisanslanmıștır.

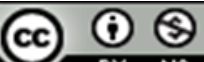

